\title{
Stigmatisation of a Formerly Obese Young Female
}

\author{
Sonia A. Tucci Emma J. Boyland Jason C.G. Halford Joanne A. Harrold \\ Kissileff Laboratory for the Study of Human Ingestive Behaviour, School of Psychology, \\ University of Liverpool, Liverpool, UK
}

\section{Key Words}

Obesity · Overweight · Gender · BMI · Fat Phobia Scale

\begin{abstract}
Background: Weight loss does not necessarily decrease the negative appraisal of a formerly overweight individual. Since past weight history tends to be disclosed in several contexts, this study aims to investigate whether negative appraisals are gender-specific and if they are modulated by the evaluators' own BMI. Methods: 202 young adults (106 male and 96 female) viewed a picture of a young attractive female (target) accompanied by one of two statements about her past weight (overweight (OW) or always kept a normal weight (NW)), and then rated her using the Fat Phobia Scale (FPS). Results: Female evaluators rated the target with the OW statement more negatively than the target with the NW statement. In contrast, males exposed to the OW statement rated the target as having fewer emotional/psychological problems and being less stupid/uncreative. BMI only influenced ratings in males, where those with higher BMI ascribed more negative attributes to the target with the NW statement than the OW statement. Conclusion: Information on weight history impacts upon the appraisal of peers. These effects are dependent on gender and BMI. Knowing that a young female was overweight triggered negative evaluations from females but did not appear to impact the judgment of males.

(c) 2013 S. Karger GmbH, Freiburg
\end{abstract}

\section{Introduction}

Obesity carries significant negative psychological consequences, some of which arise from negative attitudes toward the obese [1]. The perpetuation of such attitudes is held by some in popular culture to be an important motivation for the individual to lose weight, the reward being greater social acceptance. However, even after weight loss has occurred, past 
weight history may have a dramatic effect on perceptions of an individual, particularly those relating to self-control, personal habits, and personality [2, 3].

Obesity stigma appears to arise from the co-occurrence of a widespread belief that body weight is entirely under volitional control and an exaggerated media preference for and focus on thinness, particularly in women [4]. Obesity is undesirable and the obese are often negatively evaluated on a number of attributes $[5,6]$. Unlike stigmatisation related to race, age, and gender, negative attribution associated to obesity is influenced by causal beliefs and responsibility [7, 8]. Overweight people are seen as having a moral flaw that is deserving of blame [7]. In this sense, weight-based stigmatisation is similar to illness stigmas associated with smoking, alcohol, and sexual activity. The condition is a consequence of 'bad' behaviour [9] contracted in 'unseemly' circumstances [10]. Emphasising personal responsibility for obesity increases negative stereotypes. However, knowledge of the complex aetiology of obesity (such as biological and genetic contributors) does not necessarily improve attitudes $[11,12]$. For diseases such as HIV/AIDS, though, stigmatisation is recognised as an obstacle to treatment, whereas weight stigma has been suggested by some as a method for obesity control $[13,14]$. Although negative stigmatisation could lead to detrimental psychological consequences, on the one hand, research has found that it also correlated with more successful weight loss and weight maintenance after loss $[15,16]$. On the other hand, there are reports that have shown that stigmatisation of the obese has a negative impact at both individual and societal levels since it hinders psychological well-being and motivation [17, 18].

Compared to the literature on obesity, very limited research is devoted to the discrimination of the formerly obese. With the rise of obesity, the number of people likely to suffer discrimination either in the obese or post-obese state (having successfully lost weight) is increasing. Previous studies reported that, contrary to expectation, knowing that a female successfully lost weight impacted negatively on the impression that others had of her [19]. Compared with normal-weight or even overweight individuals, a person who lost weight can trigger a particularly strong dislike. A study by Blaine et al. [3] found that formerly overweight females were 'disliked' significantly more than their normal-weight or overweight counterparts. Three reasons were proposed for this: that losing weight i) confirms the view that weight is controllable; ii) threatens the validity of the stereotype that sees obese individuals as lazy; and iii) could make weight more salient which would in turn prompt further stereotyping. The first reason is supported by a study that employed 'before and after' weight loss treatment pictures of a target individual. Participants who saw both pictures rated the target more negatively and indicated that weight was more easily controllable than participants who viewed only the 'before' or 'after' image [2]. Bullock et al. [20] have highlighted that attitude towards the formerly overweight is modified by the perceived effort of losing weight. Thus, if high effort is perceived, the evaluators tend to rate in a more positive way than if no effort is perceived. This has been confirmed in other studies where the evaluators' attitudes are modified by knowledge of the method of weight loss; for instance, individuals who lost weight through bariatric surgery are stereotyped in a similar way to obese individuals $[21,22]$.

In terms of gender differences studies have reported conflicting results. Some have reported that women seem to be more negative in their attitudes toward overweight people and fatness than men [23-25]. This may relate to the specific media obsession with female thin body shape, whereas the male ideal image is associated with increased muscle mass. These negative attitudes tend to extend to females who have successfully lost weight regardless of the method. An explanation offered to support this attitude is that females perceive a formerly overweight female target as having personality flaws such as poor selfcontrol and laziness that allowed them to gain weight. This flaw, and therefore the potential 
to regain weight, still remains after weight loss. In contrast, there are studies which report that whereas implicit attitudes are not influenced by gender, males express more negative explicit attitudes towards overweight people [26]; however, the extension of these attitudes to the formerly overweight was not addressed. Given the conflicting evidence this is an issue that warrants further investigation.

When considering weight status differences, social identity theory postulates that members of a distinct group are more likely to view group members in a more positive light and members of the out-group more negatively [27]. Overweight individuals, however, appear to lack this 'in-group' preference and instead often hold many of the same out-group negative attitudes towards other overweight individuals [28]. An explanation that has been offered for this is that overweight people might see themselves as only belonging to this group in a temporary fashion and therefore not identifying with the group [3]. Furthermore, a study by Geier et al. [2] found that both overweight and normal-weight participants believed in the controllability of weight, and this belief showed a tendency to increase with the participants' own BMI. Nevertheless, data here remain equivocal $[29,30]$ since other studies have found that the magnitude of anti-fat biases actually appears weaker among people with a high BMI compared with those with a low BMI $[25,31]$. Since studies with overweight individuals have reported equivocal results, for the purpose of this research we cannot make predictions on the influence that BMI might have on attitudes.

Today much of the research on obesity discrimination has focused on the current weight status of the individual; however, we know that obesity discrimination can have an impact on perceptions beyond this (for instance, partners of the obese are often attributed the same negative connotations). Weight history is a particularly important variable as individuals must often disclose this under medical information not only in accessing treatment but also in situations such as employment, insurance (other than health) as well as being disclosed in social situations. The current study aims to investigate the effect of gender on evaluations of a formerly obese young female and whether the evaluator's BMI impacts on those perceptions.

\section{Participants and Methods}

\section{Participants}

Participants were University of Liverpool students (106 males and 96 females), chosen via opportunity sampling. There was no significant difference between male and female ages $(19.3 \pm 1.52$ vs. $20.0 \pm 1.56$ years) or BMI ( $23.09 \pm 3.24$ vs. $\left.22.21 \pm 3.59 \mathrm{~kg} / \mathrm{m}^{2}\right)$. The BMI $\left(\mathrm{kg} / \mathrm{m}^{2}\right)$ cut offs were $<25$ for normal weight, 25-29.9 for overweight, and $>30$ for obese. The BMIs for males ranged from 16.8 to $35.4 \mathrm{~kg} / \mathrm{m}^{2}$ (76 normalweight, 28 overweight, and 2 obese) and for females from 15.2 to $32.0 \mathrm{~kg} / \mathrm{m}^{2}$ (77 normal-weight, 15 overweight, and 4 obese).

\section{Materials}

Participants were presented with a picture of a normal-weight (BMI: $20 \mathrm{~kg} / \mathrm{m}^{2}$ ) young attractive female and one of two core statements suggesting the fictional character had either i) always retained the same weight (normal-weight condition) or ii) that she was previously obese (overweight condition).

The 50-item Fat Phobia Scale (FPS) was used [25]. The scale measures individuals' degree of negative attitudes towards obese persons. The scale has reliable internal consistency, factor structure, construct, and content validity. The internal consistency for the total scale, as well as for the six subscales identified by factor analysis, meets criteria that are commonly cited in the literature [32].

The items in the FPS are grouped into six subscales which identify different components of anti-fat attitudes, i.e., those identifying individuals as being undisciplined, inactive, and unappealing (14 items); being grouchy and unfriendly (10 items); having poor hygiene (7 items); demonstrating passivity (10 items); having emotional/psychological problems ( 5 items); and being stupid/uncreative ( 4 items). 
Tucci et al.: Stigmatisation of a Formerly Obese Young Female

Fig. 1. Overall means score in the Fat Phobia Scale (scores range from 1 to 5$) .{ }^{* * *} \mathrm{p}<0.001$.

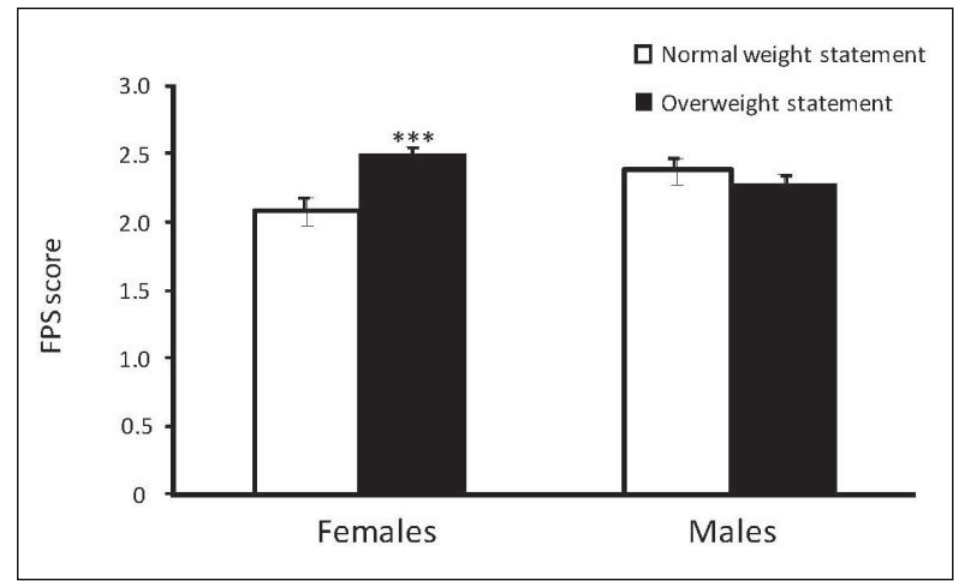

\section{Procedure}

The present study used a between-subjects design. The independent variables were the participant's gender, BMI, and statement viewed (normal-weight (NW) or overweight (OW) condition). The dependent variable was the FPS scores. After collecting the participants' details (age, gender, height, and weight), they were randomly assigned to either the NW statement or the OW statement condition. Participants were presented with the picture and the statement and were then asked to rate the individual in the picture using the criteria provided in the FPS. The description of the woman was as follows (the sentence in brackets was the only difference between statements and replaced the previous sentence in the NW condition):

'The picture above shows Jane, she is mid-20s and a graduate who works in I.T. Jane is the youngest of 3 siblings and her parents divorced around 10 years ago. Jane likes animals and romantic comedies. As hobbies Jane goes to the gym three times a week, she used to weigh 16 stone/size 24 (As hobbies Jane goes to the gym three times a week, she has always kept a healthy weight). Last year Jane learnt to drive and she now drives a silver car.'

108 (57 males and 51 females) participants were shown the OW statement and 94 (49 males and 45 females) were shown the NW statement. On completion participants were fully debriefed.

\section{Statistical Analysis}

Data were analysed using SPSS version 16.0 for Windows (SPSS Inc., Chicago, US). For the overall FPS score a univariate linear model with two fixed factors (gender (male and female) and condition (NW and OW statement)) was used. For the subscale scores a repeated measures model with two between-subjects factors (gender and condition) was used. A correlational analysis was used to examine the relationship between the participants' BMIs and FPS scores.

\section{Results}

The analysis of the FPS scores showed a significant effect of condition $(F(1,198)=4.9$; $p=0.028)$ and an interaction between gender and condition $(F(1,198)=11.23 ; p=0.001)$. Women had higher levels of fat phobia towards the person with the OW past statement (2.51 $\pm 0.05)$ when compared to the person with the NW past statement $(2.08 \pm 0.10$; $t(94)=3.9$; $\mathrm{p}=0.000$ ). Among men there was no significant effect (fig. 1).

When analysing the subscales, a significant interaction between subscale score, gender, and condition was found $(\mathrm{F}(5,990)=2.5 ; \mathrm{p}=0.03)$. There was also a significant interaction between subscale score and condition $(F(5,990)=4.7 ; p=0.000)$ but no significant interaction between subscale score and gender. Significant gender effects on subscale scores were only identified when considering responses to the OW statement independently $(\mathrm{F}(5,530)=$ 
Tucci et al.: Stigmatisation of a Formerly Obese Young Female

Fig. 2. Subscale means for men and women exposed to overweight statements (scores range from 1 to 5 ). ${ }^{*} \mathrm{p}<0.05 ;{ }^{* *} \mathrm{p}<0.01$.

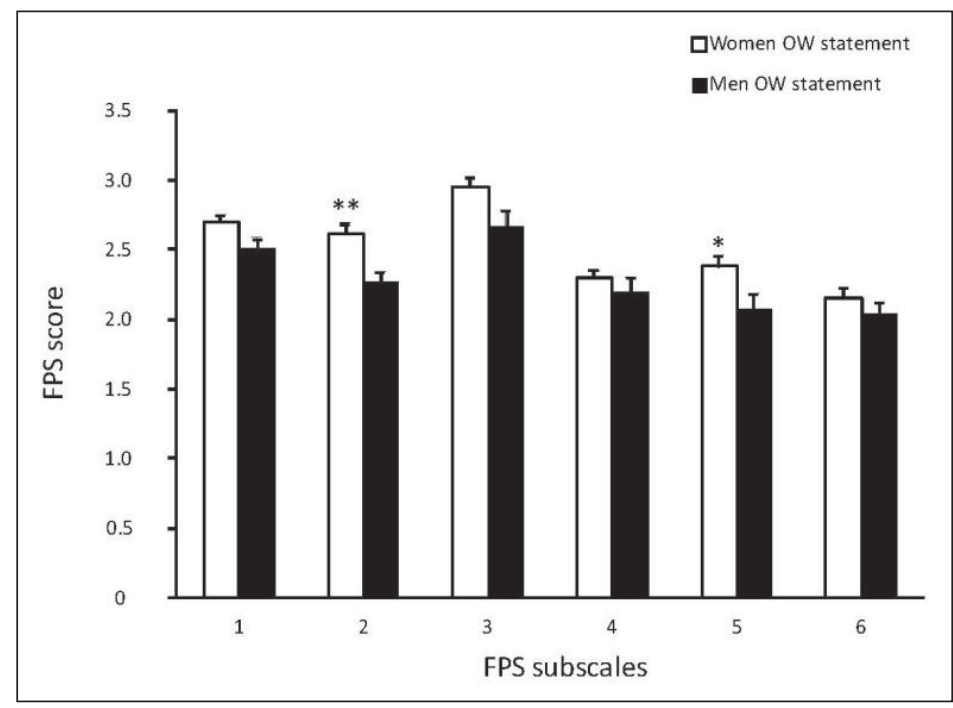

Table 1. Means and standard errors for fat phobia subscales

\begin{tabular}{lllll}
\hline Subscale & \multicolumn{2}{c}{ Females (n=96) } & Males (n=106) \\
& NW statement & OW statement & NW statement & OW statement \\
\hline 1: Undisciplined/inactive/unappealing & $2.06 \pm 0.10$ & $2.69 \pm 0.09 * * *$ & $2.32 \pm 0.88$ & $2.51 \pm 0.81$ \\
2: Grouchy/unfriendly & $2.10 \pm 0.10$ & $2.60 \pm 0.10^{* * *}$ & $2.47 \pm 0.98$ & $2.27 \pm 0.07^{\dagger \dagger}$ \\
3: Poor hygiene & $1.96 \pm 0.12$ & $2.95 \pm 0.11^{* * *}$ & $2.42 \pm 0.11$ & $2.67 \pm 0.11$ \\
5: Emotional/psychological problems & $2.14 \pm 0.11$ & $2.38 \pm 0.11$ & $2.51 \pm 0.11$ & $2.08 \pm 0.10^{* \dagger}$ \\
6: Stupid/uncreative & $2.26 \pm 0.11$ & $2.14 \pm 0.09$ & $2.35 \pm 0.10$ & $2.04 \pm 0.09^{*}$ \\
\hline & \\
&
\end{tabular}

23.4; $\mathrm{p}=0.000)$. This effect was significant in both females $(\mathrm{F}(5,250)=18.9 .4 ; \mathrm{p}=0.000)$ and males $(F(5,280)=8.6 ; p=0.000)$ (fig. 2). The means and standard errors for each individual subscale can be found in table 1 . When analysing each scale separately the following was found:

Subscale 1: Undisciplined/inactive/unappealing. For this subscale there was a significant effect of condition $(\mathrm{F}(1,198)=22.2 ; \mathrm{p}=0.000)$ and a significant gender $\times$ condition interaction $(F(1,198)=6.4 ; p=0.012)$. Women rated the picture accompanied with the OW statement more negatively than the one with the NW statement $(\mathrm{t}(94)=5.2 ; \mathrm{p}=0.000)$. Among men there was no significant effect.

Subscale 2: Grouchy/unfriendly. For this subscale there was a significant gender $x$ condition interaction $(F(1,198)=13.3 ; p=0.002)$. Women rated the picture with the $0 \mathrm{~W}$ statement more negatively than the one with the NW statement $(\mathrm{t}(94)=3.58 ; \mathrm{p}=0.001)$. This effect was not seen in men. When comparing male and female responses to the $\mathrm{OW}$ statement it was found that women gave more negative attributes to the female in the picture than men $(\mathrm{t}(106)=3.038 ; \mathrm{p}=0.003)$.

Subscale 3: Poor hygiene. For this subscale there was a significant effect of condition (F $(1,198)=31.0 ; p=0.000)$ and a significant gender $\times$ condition interaction $(F(1,198)=10.8$; 
$\mathrm{p}=0.001)$. Women rated the picture with the $\mathrm{OW}$ statement more negatively than the one with the NW statement $(\mathrm{t}(94)=6.5 ; \mathrm{p}=0.000)$. Among men there was no significant effect.

Subscale 4: Passivity: No significant effects were found for this subscale.

Subscale 5: Emotional/psychological problems. For this subscale there was a significant gender $\times$ condition interaction $(F(1,198)=9.9 ; p=0.002)$. Males rated the picture with the OW history more positively than the picture with the NW history ( $\mathrm{t}(94)=2.72 ; \mathrm{p}=0.008)$. Among the women there was no significant effect. When comparing male and female responses to the OW statement it was found that women gave more negative attributes to the female in the picture than men $(\mathrm{t}(106)=2.21 ; \mathrm{p}=0.03)$.

Subscale 6: Stupid/uncreative: For this subscale there was a significant effect of condition $(\mathrm{F}(1,198)=4.1 ; \mathrm{p}=0.045)$. Males rated the picture with the OW statement less negatively than the one with the NW statement $(\mathrm{t}(94)=2.37, \mathrm{p}=0.019)$. Among women there was no significant effect.

\section{BMI, Fat Phobia Scale, and Picture Rating Analysis}

There was a positive correlation between the BMI of the males that were shown the NW statement and the total FPS score ( $\left.r=0.336^{*} ; \mathrm{p}=0.018\right)$. Thus, the higher the BMI of the man, the more negative attributes he gave to the female with the neutral statement. The same was observed in subscales $1\left(\mathrm{r}=0.386^{* *}, \mathrm{p}=0.006\right), 2\left(\mathrm{r}=0.371^{* *} ; \mathrm{p}=0.009\right) 3\left(\mathrm{r}=0.314^{*} ; \mathrm{p}=\right.$ $0.028)$, and $4\left(r=0.304^{*} ; p=0.033\right)$. There was no relationship between the female's BMI and total FPS and no correlation between any of the conditions and subscales.

\section{Discussion}

Previous studies have found that, consistent with mate selection theory, there are no gender differences in female attractiveness ratings [33]. The results of this study suggest, however, that knowing that a female was overweight in the past can affect these evaluations among women. Thus, this appraisal process can be biased by the knowledge that a normalweight young female was overweight in the past, even if she is successfully maintaining a healthy weight. A second important finding is that the lack of gender differences observed when judging a normal-weight individual disappears when the evaluator is informed about her past weight history. We found a gender effect where overall women exert more fat phobic attitudes than men towards the female that used to be overweight. These findings are in line with the majority of previous research which has shown that women seem to be more negative in their attitudes toward fat people and fatness than men [23-25].

When analysing the FPS subscales, it was found that women consider a person that was overweight in the past to be more undisciplined, inactive, unappealing, unfriendly, and with poor hygiene. Previous findings have shown that overweight individuals are given more negative attributes such as being lazier, less healthy, less confident, less hard-working, and less happy than normal-weight individuals $[14,34,35]$. This could indicate that female evaluators may apply similar stereotypes to obese and formerly obese individuals. Previous reports have proposed that a reason why formerly overweight individuals are stigmatised is that losing weight reaffirms the preconception that weight is controllable [2]. In this study, consistent with previous reports, it can be seen that female evaluators still give the formerly overweight woman attributes that are associated with lack of control, such as being lazy and less hard-working. An aspect that is particularly interesting is that female evaluators consider a woman that has always kept a healthy weight more active than a woman that has been obese in the past. This is despite the fact that the statement in both conditions clearly says that the subject exercises regularly. This could be explained by a triggering of categorical thinking 
(labelling the individual as fat) induced by weight salience. Blaine et al. [3] proposed that formerly overweight individuals are stigmatised in part because knowing that they were overweight increases weight saliency. This in turn increases categorical thinking which ultimately prompts stereotyping [36]. In addition, by knowing that she was formerly overweight, the evaluators assume that the woman was inactive at some point in her life and that is why she became overweight and that trait could still be present despite the fact that they are told that she exercises. Nevertheless, it is important to note that the relevant subscale in the FPS groups active with undisciplined and unappealing; therefore, it remains difficult to understand the role of perceived activity alone.

On the whole, the past weight history of the target female did not seem to influence the judgements made by the male participants. For the overall results as well as for most subscales there were no significant differences between the conditions which could mean that males use the actual features in the picture rather than the statement to make the evaluations. This could relate to the mate selection processes in men where visual clues take precedence; particularly in this case as the current experiment used a picture of an attractive young woman. Eye tracking studies have shown that men spend a lot of time looking at the female body [37] and that of all the features observed, shape and weight seem to be the most relevant ones [38]. Interesting to note is that when men took into account the past history of the female they behaved in the opposite way to the women; i.e., they tended to give more positive attributes to the woman that was obese in the past. This was specific for emotional problems, stupidity, and lack of creativity; suggesting that men think that a female who had the will power to lose weight is less likely to suffer from the above-mentioned features. Although previous studies have found that men and women use different adjectives to characterise overweight individuals $[39,40]$, the general agreement is that men, similarly to women, tend to view normal-weight females in a more favourable way [41]. This study has shown that this favourable perception can be enhanced in males by informing them that the female had previously been overweight. This could be because they see her losing weight as a positive endeavour on her part.

In terms of psychological well-being, weight loss is undoubtedly advantageous (women report a dramatic life change with a remarkable increase of confidence and self-esteem] [42, 43]. However, the levels of perceived discrimination, at least in women who lose weight through bariatric surgery, can increase as evaluators feel that they took the easy way out [44]. Our results suggest that such discriminatory attitudes could generalise to at least young women who lose weight regardless of the weight loss method. This contradicts previous findings [22] where not knowing the method of weight loss led to positive evaluations. It is important to note, however, that methodological differences could have led to this discrepancy as Fardouly and Vartanian [22] used 'before' and 'after' pictures in their study. Consistent with this, the study by Mattingly et al. [21], which used a similar design with only one image presented, reported findings similar to the current study. Providing weight history information without an accompanying image and measuring obesity prejudice using different scales can yield differing findings. However, in the case of Latner et al. [45] findings appear consistent despite this methodological variety. Future designs should consider the specific image used as a design feature and may need to incorporate multiple stimuli, though.

When taking into account the participant's BMI, it was observed that only the BMI of men who were exposed to the NW statement correlated positively with subscales $1,2,3$, and 4 of the FPS and the overall score. This means that men with a high BMI tended to give more negative attributes to the female with the neutral statement. If the men are given the information that she was overweight in the past the correlation is lost, which could mean amongst other things that she could be considered an 'in-group' member. In addition, when considering a potential mate, a man with a high BMI could think that a female who had been over- 
weight in the past could be more sympathetic towards him. The lack of correlation between BMIs and weight bias has been found in previous studies [46-48] and suggests the absence of a preference, or in-group bias, among overweight individuals. Nevertheless, these results need to be interpreted with some caution as, although the BMI range of the participants was wide, there were only two male participants with a BMI greater than $30 \mathrm{~kg} / \mathrm{m}^{2}$.

This study only evaluated attitudes of young individuals towards an attractive young female. Although interesting findings are reported, the study has several limitations. The population was self-selected, and since it consisted of undergraduate psychology students, their ages, backgrounds, and education levels were relatively homogenous. Thus, these findings cannot be extrapolated to the general population and require further exploration. In addition, in this study the target was a Caucasian female. As discussed above, gender differences in anti-fat attitudes have been reported; thus, it is also possible that weight loss in females might be perceived differently than in males. Ethnicity could also influence perceptions and therefore is a topic worth exploring. Ideal body types differ markedly between ethnic groups and this is likely to influence the rater's perception. However, it is yet to be determined whether racial differences in the individual being rated would have an effect on study outcomes. This certainly warrants further investigation. Another consideration is that the FPS was originally designed to assess general attitudes toward obese people, whereas this study asked participants to apply the FPS to an individual who had been previously overweight. However, this is not necessarily a disadvantage since the limiting issue of social desirability identified by the creators is negated when rating a lean image. Furthermore, as a trend towards increased obesity discrimination with age has been reported [49], attitudes of older individuals should be explored.

A number of studies have demonstrated that obesity discrimination extends to health care settings. Health care professionals share the negative attitudes towards overweight individuals with the general population [50]. Importantly, even personnel involved in obesity management display anti-fat attitudes [51]. Health care settings constitute environments where weight history is more likely to be disclosed and could possibly, according to current results, change perceptions and attitudes which are particularly important in this context. Where weight status affects clinical decision making beyond the medical complications associated with obesity such prejudices are a matter of considerable concern, warranting further investigation. Thus, future research could aim to evaluate the specific attitudes of healthrelated professionals.

In conclusion, it can be said that, as predicted, the female with the OW statement was rated more negatively by female evaluators than the female with the NW statement. In contrast, men seemed to be more sympathetic toward the female with the OW statement. There are two main implications of these findings. Firstly, women might think that disclosing that they have successfully lost weight is a positive point. They may believe that this might help them gain social approval providing them with reinforcement for healthy changes to their lifestyle. However, these data demonstrate that actually the opposite occurs if the person receiving this information is a woman. Secondly, although losing weight has tremendous advantages in all aspects, our data suggest that the stigma of being overweight endures despite the considerable effort required.

\section{Disclosure Statement}

We wish to confirm that there are no known conflicts of interest associated with this publication and that there has been no significant financial support for this work that could have influenced its outcome.

We confirm that the manuscript has been read and approved by all named authors and that there are no other persons who satisfied the criteria for authorship but are not listed. 
Tucci et al.: Stigmatisation of a Formerly Obese Young Female

We further confirm that the order of authors listed in the manuscript has been approved by all of us.

We confirm that we have given due consideration to the protection of intellectual property associated with this work and that there are no impediments to publication, including the timing of publication, with respect to intellectual property. In so doing we confirm that we have followed the regulations of our institutions concerning intellectual property.

\section{References}

1 Kim SH, Willis LA: Talking about obesity: news framing of who is responsible for causing and fixing the problem. J Health Commun 2007;12:359-376.

-2 Geier AB, Schwartz MB, Brownell KD: 'Before and after' diet advertisements escalate weight stigma. Eat Weight Dis 2003;8:282-288.

-3 Blaine BE, DiBlasi DM, Connor JM: The effect of weight loss on perceptions of weight controllability: implications for prejudice against overweight people. J Appl Biobehav Res 2002;7:44-56.

4 Rodin M, Price J, Sanchez F, McElligot S: Derogation, exclusion, and unfair treatment of persons with social flaws: controllability of stigma and the attribution of prejudice. Pers Soc Psychol Bull 1989;15:439-451.

5 Goffman E: Stigma: Notes on the Management of Spoiled Identity. New York, Simon and Schuster, 1963.

6 Jones E, Farina A, Hastorf A, Markus H, Miller D, Scott R: Social Stigma: The Psychology of Marked Relationships. New York, Freeman, 1984.

7 DeJong W: Obesity as a characterological stigma: the issue of responsibility and judgments of task performance. Psychol Rep 1993;73:963-970.

8 Dejong W: The stigma of obesity: the consequences of naive assumptions concerning the causes of physical deviance. J Health Soc Behav 2003;21:75-87.

-9 Puhl RM, Heuer CA: Obesity stigma: important considerations for public health. Am J Public Health 2010;100: 1019-1028.

-10 Herek GM, Capitanio JP, Widaman KF: Stigma, social risk, and health policy: public attitudes toward HIV surveillance policies and the social construction of illness. Health Psychol 2003;22:533-540.

11 Puhl RM, Schwartz MB, Brownell KD: Impact of perceived consensus on stereotypes about obese people: a new approach for reducing bias. Health Psychol 2005;24:517-525.

12 Daníelsdóttir S, O’Brien K, Ciao A: Anti-fat prejudice reduction: a review of published studies. Obes Facts 2010; 3:47-58.

$\checkmark 13$ Averett S, Korenman S: Black-white differences in social and economic consequences of obesity. Int J Obes Relat Metab Disord 1999;23:166-173.

14 Hebl MR, Heatherton TF: The stigma of obesity in women: the difference is black and white. Pers Soc Psychol Bull 1998;24:417-426.

15 Latner JD, Wilson GT, Jackson ML, Stunkard AJ: Greater history of weight-related stigmatizing experience is associated with greater weight loss in obesity treatment. J Health Psychol 2009;14:190-199.

16 Latner JD, Ciao AC: Weight-loss history as a predictor of obesity treatment outcome: prospective, long-term results from behavioral, group self-help treatment. J Health Psychol 2013;DOI: 10.1177/1359105312468191.

-17 Vartanian LR, Novak SA: Internalized societal attitudes moderate the impact of weight stigma on avoidance of exercise. Obesity (Silver Spring) 2011;19:757-762.

18 Wott CB, Carels RA: Overt weight stigma, psychological distress and weight loss treatment outcomes. J Health Psychol 2010;15:608-614.

19 Latner JD, Stunkard AJ: Getting worse: the stigmatization of obese children. Obes Res 2003;11:452-456.

-20 Bullock M, Stambush M, Mattingly B: Weight loss effort and anti-fat attitudes on perceptions of a target's sociability and experienced exclusion. J Appl Biobehav Res 2011;16:42-55.

-21 Mattingly BA, Stambush M, Hill AE: Shedding the pounds but not the stigma: negative attributions as a function of a target's method of weight loss. J Appl Biobehav Res 2009;14:128-144.

22 Fardouly J, Vartanian LR: Changes in weight bias following weight loss: the impact of weight-loss method. Int J Obes (Lond) 2012;36:314-319.

23 Crandall C, Biernat M: The ideology of anti-fat attitudes. J Appl Soc Psychol 1990;20:227-243.

-24 Maiman LA, Wang VL, Becker MH, Finlay J, Simonson M: Attitudes toward obesity and the obese among professionals. J Am Diet Assoc 1979;74: 331-336.

25 Robinson BE, Bacon JG, O’Reilly J: Fat phobia: measuring, understanding, and changing anti-fat attitudes. Int J Eat Disord 1993;14:467-480.

-26 O'Brien KS, Hunter JA, Halberstadt J, Anderson J: Body image and explicit and implicit anti-fat attitudes: the mediating role of physical appearance comparisons. Body Image 2007;4:249-256.

27 Tajfel H, Turner JC: Social identity theory of intergroup behavior; in Worchel S, Austin WG (eds): Psychology of Intergroup Relations. Chicago, Nelson-Hall, 1986, pp 7-24.

28 Rudman LA, Feinberg J, Fairchild K: Minority members' implicit attitudes: automatic ingroup bias as a function of group status. Soc Cogn 2002;20:294-320.

29 Davison KK, Birch LL: Predictors of fat stereotypes among 9-year-old girls and their parents. Obes Res 2004; 12:86-94. 
Tucci et al.: Stigmatisation of a Formerly Obese Young Female

-30 Schwartz MB, Vartanian LR, Nosek BA, Brownell KD: The influence of one's own body weight on implicit and explicit anti-fat bias. Obesity (Silver Spring) 2006;14:440-447.

-31 Lin L, Reid K: The relationship between media exposure and antifat attitudes: the role of dysfunctional appearance beliefs. Body Image 2009;6:52-55.

32 Nunnally JC: Psychometric Theory. New York, McGraw-Hill, 1978.

-33 Tovee MJ, Cornelissen PL: Female and male perceptions of female physical attractiveness in front-view and profile. Br J Psychol 2001;92:391-402.

34 Tiggemann M, Rothblum ED: Gender differences in social consequences of perceived overweight in the United States and Australia. Sex Roles 1988;18:75-86.

35 Tiggemann M, Anesbury T: Negative stereotyping of obesity in children: the role of controllability beliefs. J Appl Soc Psychol 2000;30:1977-1993.

-36 Macrae N, Bodenhausen G, Milne A: The dissection of selection in person perception: inhibitory processes in social stereotyping. J Pers Soc Psychol 1995;69:397-407.

-37 Lykins AD, Meana M, Strauss GP: Sex differences in visual attention to erotic and non-erotic visual stimuli. Arch Sex Behav 2008;37:219-228.

-38 Tovee MJ, Maisey DS, Emery JL, Cornelissen PL: Visual cues to female physical attractiveness. Proc Biol Sci 1999;266:211-218.

-39 Young LM, Powell B: The effects of obesity on the clinical judgments of mental health professionals. J Health Soc Behav 1985;26:233-246.

40 Chetwynd SJ, Stewart GE, Powell RA: Social Attitudes Towards the Obese Physique. First International Congress On Obesity. London, 1974.

41 Hebl MR, Turchin JR: The stigma of obesity: what about men? Basic Appl Soc Psych 2005;27:267-275.

-42 Martínez Y, Ruiz-López MD, Giménez R, Pérez de la Cruz AJ, Orduña R: Does bariatric surgery improve the patient's quality of life? Nutr Hosp 2010;25:925-930.

43 Sarwer DB, Wadden TA, Moore RH, Eisenberg MH, Raper SE, Williams NN: Changes in quality of life and body image after gastric bypass surgery. Surg Obes Relat Dis 2010;6:608-614.

-44 Hayden MJ, Dixon ME, Dixon JB, Playfair J, O’Brien PE: Perceived discrimination and stigmatisation against severely obese women: age and weight loss make a difference. Obes Facts 2010;3:7-14.

45 Latner JD, Ebneter DS, O’Brien KS: Residual obesity stigma: an experimental investigation of bias against obese and lean targets differing in weight-loss history. Obesity (Silver Spring) 2012;20:2035-2038.

46 Crandall CS: Prejudice against fat people: ideology and self-interest. J Pers Soc Psychol 1994;66:882-894.

47 Latner JD, Stunkard AJ, Wilson GT: Stigmatized students: age, sex, and ethnicity effects in the stigmatization of obesity. Obes Res 2005;13:1226-1231.

48 Wang SS, Brownell KD, Wadden TA: The influence of the stigma of obesity on overweight individuals. Int J Obes Relat Metab Disord 2004;28:1333-1337.

49 Bray GA, Bouchard C: Handbook of Obesity: Clinical Applications. New York, Marcel Dekker, 2004.

50 Puhl R, Brownell KD: Bias, discrimination, and obesity. Obes Res 2001;9:788-805.

51 Teachman BA, Brownell KD: Implicit anti-fat bias among health professionals: is anyone immune? Int J Obes Relat Metab Disord 2001;25:1525-1531. 